\title{
EL SOPLO VORAZ. INTERPRETANDO LA ICONOGRAFÍA DE VENADOS EN TIWANAKU DESDE LAS POÉTICAS ANDINO-AMAZÓNICAS
}

\author{
THE VORACIOUS BREATH. INTERPRETING THE CERVID ICONOGRAPHY \\ OF TIWANAKU FROM ANDEAN-AMAZONIAN POETICS
}

juan Villanueva Criales ${ }^{A}$

En este artículo se emplea la iconografía de venados como un ingreso al mundo de la cacería tiwanakota (ca. 500-1100 DC), aspecto descuidado por la narrativa arqueológica dominante del "Estado andino" agropastoril. Se resumen poéticas andinas y amazónicas sobre venados como base para la interpretación, y se describen los objetos con imágenes de venados conocidos para Tiwanaku. En ellos, las alusiones gráficas a un poderoso soplo, a la ferocidad y consumo de humanos, así como al cielo nocturno, plantean metáforas de los glaciares andinos, la noción amazónica del venado-jaguar y la ética de la cacería en relación con entidades dueñas de los animales. Nuestra interpretación relativiza la separación tajante entre Andes y Amazonía, enfatizando sus mutuas influencias en tiempos prehispánicos.

Palabras clave: iconografía, Andes sur-centrales, cérvidos, Tiwanaku, Horizonte Medio.

This paper takes cervid iconography as an entry into the realm of Tiwanaku (ca. 500-1100 AD) hunting, an aspect that has been overlooked by the dominant archaeological narrative of the agropastoral "Andean State". We summarize Andean and Amazonian poetics about deer, and describe known Tiwanaku objects with deer imagery. On them, graphic allusions to a powerful breath, and to ferocity and human consumption, as well as to the nocturnal sky, raise metaphors of the Andean glaciers, the Amazonian notion of the deer-jaguar, and the ethics of hunting in relation to animal-owning entities. Our interpretation aims to relativize sharp Andes-Amazon divides, emphasizing mutual influences between both regions in pre-Hispanic times.

Keywords: iconography, South-Central Andes, deer, Tiwanaku, Middle Horizon.

\section{INTRODUCCIÓN}

El carácter estatal y andino ha sido clave en las consideraciones arqueológicas sobre Tiwanaku (ca. 500-1100 DC) (Ponce Sanginés 1972; Kolata 1986; Albarracín-Jordán 1996; Janusek 2008). Se ha llamado la atención sobre el contexto político del surgimiento de esta narrativa, vinculándola al nacionalismo revolucionario de 1952 y a su arqueología estatal (Angelo 2005; Michel 2009; Arnold 2016). Irónicamente, esta narrativa ha cambiado poco a pesar de la trayectoria política boliviana desde la década de 1980, tendiente a valorar la multiculturalidad y pluralidad de la sociedad, y al potenciamiento económico y político de ciudades y regiones vallunas, amazónicas y chaqueñas. En ese sentido, reflexiones recientes sugieren revertir la consideración de la sociedad tiwanakota como un fenómeno netamente andino, atendiendo a las crecientes evidencias de continuidades culturales entre diversas zonas ecológicas (Arnold 2016). Estas mutuas influencias se vienen detectando en el ámbito textil (Arnold \& Espejo 2013), cerámico (Villanueva 2018) y, al sur del Titicaca, en patrones de asentamiento e intercambio de plantas psicotrópicas (Angelo \& Capriles 2000; Angelo 2006).

\footnotetext{
A Juan Villanueva Criales, Museo Nacional de Etnografía y Folklore, Laboratorio de Estudios Ontológicos y Multiespecie, Universidad Mayor de San Andrés, La Paz, Bolivia. ORCID: 0000-0001-5239-138X. E-mail: juan.villanuevacriales@gmail.com
} 
En este texto se aborda dicha problemática desde la iconografía animal tiwanakota, específicamente la del cérvido o venado. ${ }^{1}$ Los estudios sobre el tema han tratado usualmente a los animales de yungas o tierras bajas como representaciones naturalistas que reflejan relaciones entre pisos ecológicos (Korpisaari et al. 2007; Sagárnaga 2014), o como alusiones de prácticas rituales concretas, por ejemplo, el corte de piernas (Trigo \& Hidalgo 2012). Nosotros exploraremos la iconografía del venado en diferentes soportes, y no como representaciones distantes de "naturalezas" superficiales. Dicha mirada, moderna y de carácter estructuralista, es compartida por algunos de los referentes etnográficos a los que recurrimos para entender los pensamientos andino y amazónico sobre el venado. Además, intentaremos alejarnos de esa tajante división entre mente y materia, cultura y naturaleza o representación y realidad, para comprender estos conceptos como "poéticas del habitar" (Ingold 2000: 102) que emergen de relaciones sensoriales profundas con el mundo. Las imágenes, como elementos del diseño de los materiales, pueden entenderse como herramientas para la cocreación del mundo con sus actores humanos y no humanos, pensadas para dialogar y afectar más que para representar (Escobar 2013).

Así, pensamos la iconografía de cérvidos como un ingreso a las poéticas de la cacería en Tiwanaku, una temática ignorada por aquella narrativa dominante del "Estado agropastoril andino" que cuestionamos. El hecho de pensar las imágenes como consecuencias y componentes de poéticas prehispánicas permite interpretarlas desde poéticas contemporáneas registradas etnográficamente. En este texto exploramos las relaciones que pueblos andinos y amazónicos han entablado con el venado, siguiendo una estrategia similar a la que emplea Karadimas (2014) para interpretar iconografía prehispánica del norte peruano. En su trabajo, se parte de lo contemporáneo para luego dirigir sobre las piezas arqueológicas una mirada que tiene en mente las mitologías indígenas. Esta estrategia analógica implica los problemas de cualquier extrapolación temporal entre la contemporaneidad y los tiempos prehispánicos, que consiste en pensar que una imagen mantiene el mismo significado a través del tiempo y el espacio. No obstante, y más allá de esta limitación, recurrir a visiones y ontologías andinas y amazónicas es útil para mirar el registro iconográfico con menos sesgos modernos y plantear hipótesis alternativas de interpretación. Entonces, resumiremos las poéticas andinas y amazónicas contemporáneas sobre el venado, describiremos la imaginería del venado tiwanakota y la interpretaremos a la luz de aquellas poéticas contemporáneas.

\section{POÉTICAS SOBRE EL VENADO}

\section{Las poéticas andinas}

La etnohistoria provee indicios tempranos de una poética que situaba a los animales en el cielo nocturno, tanto en el mundo quechua como en el aymara (Pucher de Kroll 1950; Urton 1981; Ibarra Grasso 1982; Sánchez et al. 2016). Los venados formaban parte de este ámbito: “[...] estas voces decían las indias y decían los filósofos que conocen en las estrellas que hay hombres y mujeres y carneros con su cría, y perdices, y cazador, y pastor, batán, león, venado" (Guamán Poma de Ayala 1993 [1615]: 899).

Poco más sabemos sobre la constelación del venado, salvo que se la denominaba Topatorca (Polo de Ondegardo 1916 [1571]: 5), y que Ibarra Grasso (1982) traduce como topa taruka, venado que embiste o venado resplandeciente.

Por contraste, el mundo andino contemporáneo relaciona fuertemente el venado y la vicuña con la montaña, mediante fragmentos poéticos como los siguientes:

Vicuña uñita / taruka uñita / jina puni kani / munasqan uñita ${ }^{2}$ (Espejo 2006: 20).

Urqukunapi tarukitas / taytay irranti waqawanqa / urqupi vikuñitas / mamay irranti llakiwanqa [... $]^{3}$ (Lienhard 2005: 492-498).

Acaso fue mi madre la vicuña de las pampas / o fue mi padre el venado de los montes / para ser errante / para andar sin descanso / por los montes y las pampas / apenas envuelto por el viento / en las abras y en los cerros (Hernández 1983: 177).

La etnografía andina otorga dueños no humanos a los venados, quienes los crían de modo análogo a como los humanos crían sus rebaños. Así, Molinié-Fioravanti (1985) documentó en Yucay, cerca de Cuzco, que los venados son bestias de carga de los apu, espíritus de las alturas. En la Cordillera Blanca de Ancash, el venado o tarugo es la vaca de los ancestros o abuelitos, una metáfora basada en atributos comunes como el tamaño, las astas, las uñas o la alimentación herbívora (Walter 2017). 
En Bolivia, Arnold y Yapita (1998) refieren al lenguaje empleado al brindar y cantar en Qaqachaka, que describe a los cérvidos como las cabras de los antiguos y prehumanos chullpas. ${ }^{4}$ En la taxonomía de Qaqachaka los venados integran el grupo de animales sallqa, de crianza no humana, que moran en la tierra junto con vicuñas y guanacos, pero con las cabras forman una subcategoría de bestias con cuernos o waxrani, propiedad de las entidades del averno, el tiyu y la tiya (Arnold \& Yapita 1992). En todo caso, el venado tiene un dueño no humano con quien se debe entablar un diálogo ritual al momento de la caza. La caza ritualizada del venado en la Cordillera Blanca enfatiza la obligación de hacer ofrendas compensatorias al dueño de los venados, cazar con moderación y no cazar al macho reproductor. La venganza del abuelito por incumplimiento de esta norma es, usualmente, el corte de testículos (Walter 2017).

Seguramente por su hábitat montañoso, el venado andino está poéticamente asociado con el interior de la tierra, la noche y los cerros. Consumir su sangre fortalece para recorrer las alturas, y su estómago, alimentado de plantas amargas, beneficia la digestión (Walter 2017: 106). Garcilaso de la Vega (1968 [1609]) hace temprana referencia al consumo de cálculos biliares o piedras bezoares de venado, de carácter curativo por la dieta amarga del animal. Una apreciación similar permanecía en La Paz hasta mediados del siglo pasado (Paredes 1963). En la Cordillera Blanca, la grasa de venado facilita partos difíciles (Walter 2017). La relación del venado con el parto, la seducción y la sexualidad transgresora se halla también en el cuento de Qaqachaka acerca del venado Lorenzo Puchali, quien se recuesta al lado de las jóvenes y se confunde con un picaflor (Arnold \& Yapita 1992: 236-237). En tiempos coloniales, Guamán Poma de Ayala describe este canto de las doncellas en la danza: "Si no pasa un venado. Tú danzas el wayku en tu mano. Si no hay algo como un ciervo. Tú danzas el wayku en tu nariz. Ay hermanito. Ay hermanita" (1993 [1615]: 321).

La poética que vincula la nariz del venado con danzar el wayku -la riada o deslizamiento de tierrapervive en la Cordillera Blanca de Ancash, donde el venado es una metáfora del glaciar, que cruje con sus exhalaciones y se desprende por sus golpes, provocando mortales waykus (Walter 2017). Según la misma fuente, el venado tiene ollares humeantes, cuyo potente soplo puede tumbar a una persona. Así como el soplo nasal es una metáfora de la avalancha, el soplo uterino se relaciona con el atawaray, el viento del fondo de las quebradas, clarificando la relación del venado con el parto (Walter 2017). ${ }^{5}$

La concepción del venado causante de estragos se basa en que, antiguamente, el venado se comía a los hombres, una idea contenida en el Manuscrito de Huarochirí del siglo xvi. En él se narran las pruebas con que Huatyacuri, hijo del poderoso Pariacaca, vence a un cuñado rico y arrogante (Millones \& Mayer 2012). En el último desafío, el venado tiene un rol central:

Y así le dijo el Huatyacuri: "Hermano, ya habéis visto cómo
no he rehusado cuanto habéis querido; razón será ahora
que vos también lo hagáis así y sea el caso que cada uno
de nosotros entre a danzar vestido de una camiseta azul y
puestos unos pañetes (los cuales llaman huara) de algodón
blanco en las partes vergonzosas, y veamos quién de los
dos trae mejor recaudo de esto y lo hace mejor". Aceptó el
desafío el rico y, como siempre lo solía hacer, salió el primero
en plaza vestido como su contrario dijo; el cual vino luego
y, con un repentino grito y corriendo, entró donde el otro
estaba bailando descuidado, el cual, del grito, de la carrera y
sobresalto repentino, echó a correr de manera que, para darse
más prisa, se volvió, o lo volvió el Huatyacuri, en venado
y así se fue hacia aquel asiento de Anchicocha que hemos
dicho muchas veces [...] el venado partió delante donde se
desapareció y se sustentó siempre de comer gente, y que,
como fuesen estos venados multiplicando, se juntaron una
vez a cierta fiesta y cantaron en ella diciendo: “Como somos
tantos, podremos comer los hombres"; y que un venadillo
pequeño erró la copla y dijo: “ ¿Cómo, si somos tantos, no
nos comerán los hombres?". Y que desde entonces ya son
comidos de ellos y no los hombres de los venados (Bendezú
$2003: 108-109$ ).

Para Renard-Casevitz (1979) el pasaje narra una serie de transformaciones mediadas por el grito y la palabra: un hombre rico se aterroriza por el grito y se transforma en un venado antropófago. Posteriormente, por una palabra equivocada, los venados pasan de cazadores a presas, de comedores a comidos.

\section{Las poéticas amazónicas}

Esta sección se basa en la notable síntesis sobre el venado en la Amazonía de Renard-Casevitz (1979). Uno de los espacios donde las sociedades amazónicas ubican al venado es la tierra cultivada, una transición entre el pueblo y el bosque. En ese sentido, los desanas del Vaupés colombiano conciben el venado como "el más humano de los silvícolas", y para los urubu-ka’apor de Maranhâo, Brasil, el venado es el alma de un humano muerto errante, "el más silvícola de los humanos". Este 
lugar intermedio explica su significado erótico, atrayendo a mujeres casadas o seduciendo niños, uniendo a seres culturalmente separados y separando parejas, transgrediendo el orden social con una belleza joven y excesiva cuya sanción es la muerte (Renard-Casevitz 1979).

La extrema vitalidad del venado le provoca un envejecimiento precoz, notorio por la caída de sus astas, que lo opone a la serpiente, eternamente joven por mudar de piel. En las poéticas amazónicas, cérvidos y ofidios se asemejan por su relación con el veneno, aunque de modo inverso. Como refieren los mitos kayapós del río Xingú, en Brasil, las serpientes son maestras de un veneno interno que inyectan en otros para matarlos; los bakairis de Mato Grosso se refieren al cariz toxicológico de los venados, que logran comer la yuca amarga robada a los humanos. El conocimiento y la valoración de la piedra bezoar del venado como contraveneno, entre las sociedades amazónicas, inducen a Renard-Casevitz (1979) a sugerir la oposición entre venado y serpiente, como metonimia de la oposición entre bezoar y veneno.

El otro espacio de los venados en las cosmovisiones amazónicas es, nuevamente, el cielo nocturno. Huxley (1960) relata que los urubu-ka'apor reconocen una estrella llamada Ojo de Ciervo, a la que los hombres disparaban flechas, obligando a los niños a hacer lo mismo para poder matar venados. Algunos autores han propuesto como una clave de la "mentalidad cazadora" ubicar a los dueños de las diversas especies animales en las constelaciones, siendo los animales proyecciones de esos dueños celestiales. Zerries (1959) cita casos de este fenómeno en toda la Amazonía, incluyendo los Llanos de Moxos en Bolivia. Residan o no en las constelaciones, los espíritus que guardan a los animales forman la base de las prácticas cinegéticas en la Amazonía. Quien maltrate a los animales ofende a su maestro y provoca su venganza, siendo la caza una reconciliación con los maestros (Renard-Casevitz 1979). El venado también tiene, frecuentemente, un rol distintivo, como por ejemplo entre los tsimanes del norte de Bolivia, para quienes el propio dios creador Dojiti se transforma en venado y después en anta (Gabriela Behoteguy, com. pers., 2020).

Existen otros casos amazónicos que, según RenardCasevitz (1979), plantean la existencia de un amo de los animales que se transforma o combina características de cérvido y felino. Los cazadores ka’apor evitan disparar a los venados por el temor de herir a Boraro. Este es un espíritu que secunda al maestro de los animales, y es descrito como un gigante peludo de enorme pene, con los pies girados, ojos incandescentes y dientes doblados y afilados, como los de un jaguar. Siendo un depredador de humanos, puede tomar la apariencia de un venado, el habitante más humano del bosque. Boraro, seductor excesivo e irresistible, sugiere vínculos con las serpientes, pues puede ingerir veneno y matar con la orina. Entre los desanas, existe un hueso que permite hacer una flauta cuyas notas son irresistibles para los venados, instrumento que atrae también al jaguar. El nombre del hueso, yé-e ama, significa literalmente el jaguar-venado, un felino que tiene el color de los ciervos, de los cuales se alimenta. Finalmente, los tikunas del Putumayo, en la Amazonía peruano-brasileña, indican que el venado era antiguamente un jaguar comedor de hombres. Con el fin de detenerlo, el dios Dyai lo golpeó debajo de la mandíbula, haciendo aparecer las astas como dos dagas a través de la cima del cráneo y convirtiendo al venado en un animal inofensivo. De este modo, un venado jaguar y caníbal se transforma en un venado cazado y comido, al igual que en el mito andino de Huarochirí (Renard-Casevitz 1979). Estas referencias llevan a la autora a conferir al venado una posición de término medio en las transformaciones, $\mathrm{o}$ conjunción de oposiciones, por la cual opera el paso de comedor a comido, como encrucijada entre juventud y vejez, vida y muerte.

Ensayaremos una comparación entre poéticas andinas y amazónicas sobre el venado detectando divergencias y convergencias. Entre las divergencias, las poéticas andinas plantean la relación metonímica del venado con los cerros, y su ubicación taxonómica entre los animales de crianza no humana mediante la metáfora del ganado, de origen agropastoril. En el ámbito de la caza andina, el venado es también una metáfora del glaciar, enfatizando su poderoso y destructivo soplo. Del lado amazónico, destaca la consideración humanizada del venado y su carácter transitorio entre espacios, además de la noción de vejez prematura y la oposición ante la serpiente, basada en el manejo y control del veneno.

Sin embargo, son más las convergencias, comenzando por la relación del venado con el erotismo, la transgresión y la muerte, sea asignando al venado una muerte prematura o incorporándolo al espacio subterráneo donde moran los muertos. Otra poética común incluye al venado y otros dueños de los animales en el cielo nocturno, aunque en la zona andina esta idea ha desaparecido en tiempos recientes. Finalmente, tanto en el caso andino como amazónico, el venado tiene 
dueños no humanos que exigen un relacionamiento social mediante ritos y normas cinegéticas a fin de evitar castigos. El venado puede transformarse en un comedor de humanos, siendo este carácter ambiguo de predador disfrazado de presa la fuente de su peligrosidad. En el ámbito andino quedan fragmentos de esta idea, mejor ejemplificada desde la etnohistoria por el Manuscrito de Huarochirí; en el mundo amazónico aún se reconocen peligrosos seres capaces de transmutar entre venado y jaguar.

\section{EL VENADO EN LA ICONOGRAFÍA DE TIWANAKU}

Antes de ingresar al ámbito de las imágenes de venado, notemos que existen evidencias del consumo y uso de este animal en la manufactura de objetos durante el Horizonte Medio. Se detectaron huesos y astas de venado en contextos arqueológicos Tiwanaku, ${ }^{6}$ aunque en proporción minoritaria frente a otras especies animales, probablemente por el poco acceso al venado en el área circumtiticaca (Webster \& Janusek 2003). En los valles cochabambinos, el uso de astas de venado como lanzaderas o wichuñas para la textilería procede de tiempos formativos (Rivera 2012). Finalmente, se trabajó la piel del venado, aunque la mala preservación de materiales orgánicos ocasiona que se encuentre poco en el registro arqueológico. En contextos excepcionales, como el hallazgo de Amaguaya -un envoltorio de materiales para inhalación de psicotrópicos en los valles altos de La Paz-, se han detectado seis a siete piezas hechas con cuero de venado andino o taruka, entre ellas bolsas, envolturas y estuches de diferentes tamaños, conteniendo la totalidad del conjunto, la tableta de inhalación y algunos ítems minerales (Capriles 2002; Loza 2007). Aunque el conjunto presenta hilos de alpaca, la mayor parte de sus componentes procede de animales que no son de rebaño: jaguar, vicuña y vizcacha.

Pasando a la iconografía, debemos definir los rasgos formales que delimitan el universo de las imágenes de venados. El trabajo de Trigo e Hidalgo (2018) incluye como características las astas, la nariz escalonada, los colmillos con labios en forma de gancho y la presencia de miembros humanos (específicamente piernas) emergiendo de la corona o los dientes. Consideramos que la nariz escalonada con grandes ollares es el atributo definitorio, que nos recuerda, como hipótesis, aquellas poéticas vinculadas con los ollares humeantes del venado y el fuerte soplo. Los labios en gancho en las imágenes bidimensionales, y engrosados en las imágenes tridimensionales, ocurren solamente en relación con la nariz escalonada, siendo otro rasgo definitorio. Los colmillos, en cambio, aparecen también en cabezas de serpiente, felino o humano (fig. 1) y se encuentran ausentes de ciertas imágenes de nariz escalonada, al igual que las astas. En cuanto al cuerpo, hemos observado que los seres con cabeza de venado nunca tienen cuerpo de venado, sino manos y brazos humanos, patas de felino, alas y cola de ave. No existen imágenes de una pata ungulada con cuatro dedos, equivalente a la pata de dos dedos que identifica a los camélidos.

El venado no es una imagen frecuente en Tiwanaku, apareciendo en proporción menor a las aves, los felinos y los humanos, e incluso que los ofidios, los camélidos y los peces. No obstante, se presenta en variados soportes: textiles, cerámica, hueso trabajado y tallas de madera, además de esculturas de mediano y pequeño tamaño, siempre en bulto y nunca en bajorrelieve. Existen imágenes de cérvidos tridimensionales en piedra, cerámica modelada y madera, y bidimensionales en textiles, hueso grabado y cerámica pintada. Hasta ahora no se conocen, en el arte de Tiwanaku, figuras anatómicamente exactas de venados de cuerpo entero, un tratamiento de la imagen que tiene como componentes casi exclusivos a los camélidos de rebaño y las aves lacustres. ${ }^{7}$ Hecha esta aclaración, hemos dividido las imágenes de cérvidos en tres temas: el humano-cérvido con hacha o decapitador venado, como le llaman Trigo e Hidalgo (2018); el cérvido astado con miembros cercenados o venado devorador, y las astas de cérvido formando parte de otros temas, fundamentalmente del humano sedente o cazador.

\section{El decapitador venado}

Este tema se desprende de una amplia gama de imágenes de decapitadores, personajes erguidos que sostienen hachas y cabezas humanas, pero cuyas cabezas y otros atributos son animales. Trabajos recientes proveen extensas descripciones del decapitador, sobre todo en sus versiones felínica o chachapuma (Sagárnaga \& Korpisaari 2007), cérvida (Trigo \& Hidalgo 2018) y camélida (Baitzel \& Trigo 2019). La definición del cérvido que ensayamos, basada en la nariz escalonada, nos permite ampliar la recopilación de Trigo e Hidalgo (2018). El primer conjunto de decapitadores venados 


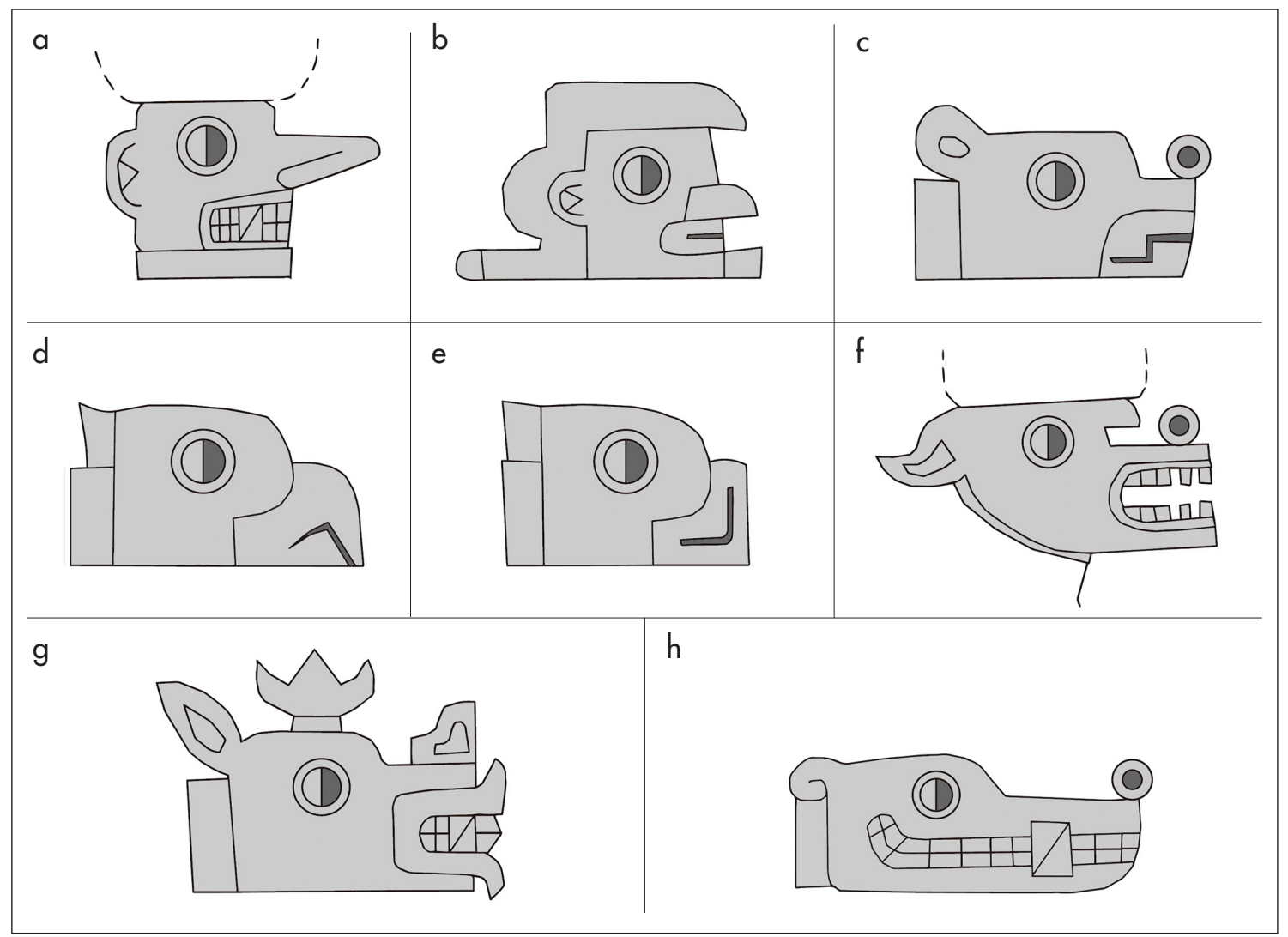

Figura 1. Clasificación simplificada de cabezas animales de perfil en iconografía tiwanakota: a, b) humanos; c) felino; d) ave; e) pez; f) camélido; g) cérvido; h) ofidio. Figure 1. Simplified classification of animal heads in profile in Tiwanaku iconography: $\boldsymbol{a}, \boldsymbol{b}$ ) humans; $\boldsymbol{c}$ ) feline; d) bird; e) fish; f) camelid; $g$ ) cervid; h) ophidian.

está integrado por esculturas en piedra de varias decenas de centímetros de alto. Cuatro de estas piezas fueron incluidas por Sagárnaga y Korpisaari (2007) en la categoría de hombre-felino. Los colmillos con labios reforzados y la nariz escalonada, de frente triangular y ollares delanteros (fig. 2a y b), los distinguen de los hocicos redondos con ollares laterales de los felinos. Estos decapitadores, sea en postura sentada o arrodillada, sostienen hachas y cabezas humanas, y parecen desprovistos de astas. Una versión en miniatura del tema es la figurilla PRT0177, de la ofrenda de Pariti (fig. 2c), esculpida en caliza con ojos incrustados de piedra azul. En ese caso, el venado carece de colmillos, pero presenta dos agujeros sobre la cabeza, que llevaron a Sagárnaga y Korpisaari (2007) a presumir que habría tenido astas incrustadas, correspondiendo por tanto a un cérvido.

El tema del decapitador venado se expresa también en la cerámica modelada. Al respecto, el estudio de Sagárnaga y Korpisaari (2007) menciona decapitadores cerámicos procedentes de un rasgo de ofrenda exhumado por pobladores de Pariti, la mayor parte con atributos felínicos. La pieza PRT00001 (fig. 2d), su par PRT00046, los fragmentos PRT00428 y PRT00013, y una pieza similar recuperada en Huatajata poseen labios engrosados sin colmillos y nariz triangular con ollares frontales. Por lo que se puede apreciar en las piezas más completas, el personaje se encuentra de pie, sosteniendo un hacha y una cabeza humana, y posee sobre su cabeza un orificio donde se incrustarían las astas. La cola, aplanada, a diferencia de la cola redonda de los felinos, remataría presumiblemente en una pluma o cola de ave, similar a los venados devoradores que veremos en la sección siguiente.

Una sola tableta de madera de la colección de San Pedro de Atacama (Torres 1987: 235; Llagostera 2006: 113) (fig. 2e) presenta rasgos de cérvido, combinando 


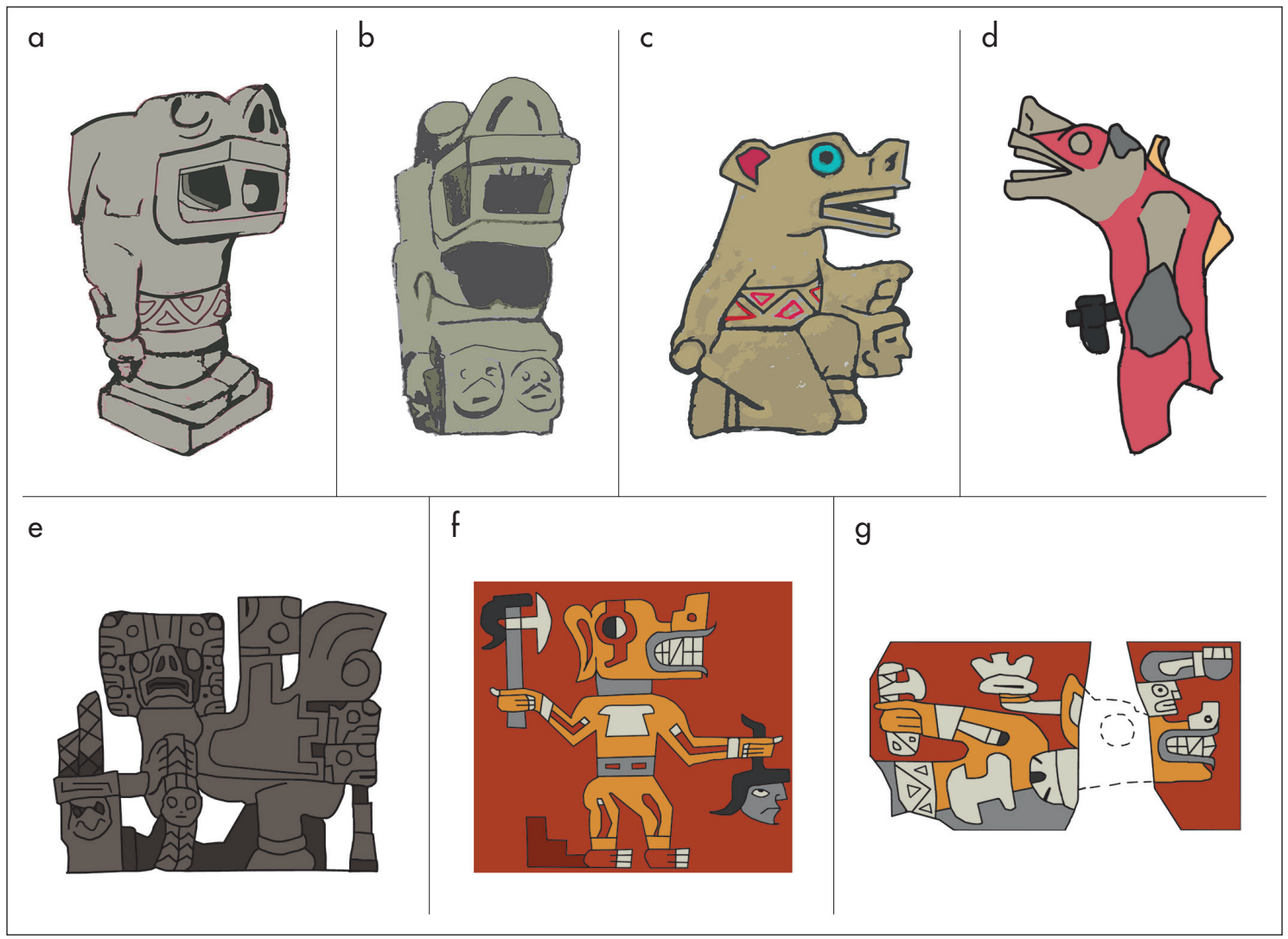

Figura 2. Ejemplos del tema del decapitador venado: a, b) esculturas (sobre la base de Sagárnaga \& Korpisaari 2007); c) figurilla de Pariti (sobre la base de Korpisaari \& Pärssinen 2011); d) cerámica de Pariti (sobre la base de Sagárnaga \& Korpisaari 2007); e) tableta de madera de San Pedro de Atacama (sobre la base de Llagostera 2006); f) keru de Tiwanaku (sobre la base de Posnansky 1957); g) fragmentos de keru de Putuni, Tiwanaku (sobre la base de Trigo \& Hidalgo 2018). Figure 2. Examples of the beheader deer motif: $\boldsymbol{a}, \boldsymbol{b}$ ) sculptures (based on Sagárnaga \& Korpisaari 2007); c) Pariti statuette (based on Korpisaari \& Pärssinen 2011); d) Pariti pottery (based on Sagárnaga \& Korpisaari 2007); e) wooden tablet from San Pedro de Atacama (based on Llagostera 2006); f) keru from Tiwanaku (based on Posnansky 1957); g) keru fragments from Putuni, Tiwanaku (based on Trigo \& Hidalgo 2018).

tallado tridimensional con iconografía bidimensional en bajorrelieve. El personaje, encorvado o a punto de incorporarse, sostiene el hacha y la cabeza humana. La nariz es escalonada y triangular, con grandes ollares, no posee astas ni colmillos e incorpora alas y una corona radiada.

Finalmente, las imágenes bidimensionales del decapitador venado se encuentran en cerámica pintada. El más próximo a los decapitadores modelados y esculpidos está en un keru exhumado en Tiwanaku por Bennett (1934: 115), ilustrado por Posnansky (1957: plancha $\mathrm{xx}$ ). El personaje (fig. 2f) se presenta de pie sobre fondo rojo, alternando repeticiones de color naranja y blanco. Sostiene hacha y cabeza humana, tiene nariz escalonada y labios en gancho con colmillos, pero no astas. El otro caso está formado por dos fragmentos de un keru rojo exhumados en Putuni, Tiwanaku (Couture \& Sampeck 2003), ilustrados por Trigo e Hidalgo (2018: 146), y presenta nariz escalonada y labios en gancho con colmillos y hacha (fig. 2g). Como la imagen está incompleta, no se puede asegurar la presencia de astas, pero la posición recostada y la presencia de un pie emergiendo de la corona sugieren una transición hacia el tema del venado devorador.

En los dos últimos casos se observa un elemento con forma de hacha sobre el pecho de las figuras, que también se halla presente en algunas imágenes del venado devorador. Horta (2016) ha realizado un interesante estudio acerca de la trascendencia de este "adorno de barbilla" hacia los tiempos del Intermedio Tardío y el 
Horizonte Tardío, cuando era entendido como una luna creciente. Quizá aquí hallemos alguna conexión más con el carácter nocturno del venado; sin embargo, cabe notar que este adorno de barbilla no es exclusivo de las representaciones de venado en Tiwanaku, sino mucho más generalizado.

\section{El venado devorador}

Solo existen imágenes bidimensionales del venado devorador. Se distingue del decapitador venado por no llevar hacha, desplegando siempre astas y una extremidad humana, un brazo o frecuentemente una pierna, que se desprende de los colmillos, la corona o la cabeza. Las coronas son comunes en la iconografía tiwanakota, pero solo en las imágenes de venados se encuentran extremidades humanas. La posición del venado es arrodillada o cuadrúpeda, y frecuentemente incluye un brazo humano sosteniendo un báculo, patas felínicas, cola y alas de ave. En ese sentido, se asemeja a hibridaciones de ave y felino comunes en la iconografía tiwanakota (Villanueva 2007). Este tema coincide con lo que recientemente se definió como una variante del "sacrificador" con atributos de venado o taruka, en un interesante análisis iconográfico de tubos de hueso (Horta et al. 2020).

El primer ejemplo de este tema está en un manto textil de la fase Loreto Viejo en Azapa, norte de Chile (Conklin 1983: 41). ${ }^{8}$ Esta imagen posee corona con astas y extremidad humana, nariz escalonada y colmillos, aunque se distingue por la ausencia de alas y cola de ave, y por tener dos brazos humanos, sosteniendo un báculo y un aparente felino tomado por el cuello (fig. 3a). Otros ejemplos del venado devorador provienen de tubos de hueso grabados, y han sido sistematizados por Trigo e Hidalgo (2018). Un caso proviene de una tumba en Quitor 5, en el oasis de Atacama en Chile (fig. 3b). Otros dos, uno completo (fig. 3c) y otro fragmentado, proceden probablemente de Tiwanaku y pertenecen a la colección del Musée du Quai Branly en Francia, y el cuarto (fig. 3d) se encuentra en la colección del Denver Art Museum en Estados Unidos. A ellos deben sumarse otros cinco ejemplares muy recientemente presentados por Horta y colaboradores (2020) y que, por tanto, no reproducimos en este texto. Dos de ellos provienen también de Quitor 5, uno de Quitor 6, uno de la cueva de Pulacayo, actualmente en el Museo Asur de Sucre, y el último, sin contexto claro, está en poder del Museo de Metales Preciosos Precolombinos de La Paz. Si algo caracteriza a los siete personajes, además de la nariz escalonada y los labios en gancho con colmillos, es la corona de la que emerge la extremidad humana, el cuerpo arrodillado con patas de felino, el brazo humano sosteniendo un báculo y la cola de ave. En todos estos casos se reconocen astas, y en tres de ellos también alas. Los báculos pueden presentar apéndices de cabeza de felino, o de cola de ave y cabeza humana.

Finalmente, contamos con seis imágenes de venado devorador en cerámica pintada, mayormente en vasos keru. Un fragmento de keru de Pariti (Korpisaari \& Pärssinen 2011: lámina 28) y dos de Putuni (Couture \& Sampeck 2003) muestran solamente las astas, estando demasiado incompletos para decir más. Los ejemplos completos incluyen una jarra recuperada en Kerikala, Tiwanaku (Trigo \& Hidalgo 2018: fig. 5); un vaso de Tiwanaku reportado por Posnansky (1957: plancha Xv), y el vaso PRT00219 de la ofrenda cerámica de Pariti. En estos casos, el cérvido carece de cuerpo, pues su cabeza -siempre con astas, y en dos casos con una pierna humana emergiendo de la frente o la boca- aparece suelta o adjunta a una voluta con patas de felino y alas. En los casos provenientes de Tiwanaku (fig. 3e-f), el cérvido es naranja con astas blancas, sobre rojo, y presenta un pectoral o adorno de barbilla; en el keru, figura en el registro inferior una serie de cráneos humanos. En el vaso de Pariti (figs. 3g y 4d), son cuatro cabezas de cérvido con astas blancas, dos grises y dos naranjas, sobre un panel negro yuxtapuesto a otro panel rosa, con dos serpientes naranjas en zigzag.

\section{Las astas de venado y el humano sedente}

El tercer tema es el asta, posiblemente metonimia del venado, como componente de otras imágenes. En la colección de Pariti, específicamente sobre los challadores PRT00215 y PRT00217 (fig. 4a y b), el asta de venado, un semicírculo con tres puntas de color blanco, se repite siempre sobre fondo negro, rellenando espacios ocupados por imágenes mayores, multicolores y texturadas, que han sido interpretadas como constelaciones (Villanueva 2015). Una composición similar al interior del challador PRT00241 incluye diversos motivos sobre fondo negro, entre ellos un círculo negro con cuatro puntas (fig. 4c).

Ambos motivos, el asta de venado y el círculo negro con puntas, son inusuales en la iconografía tiwanakota, 


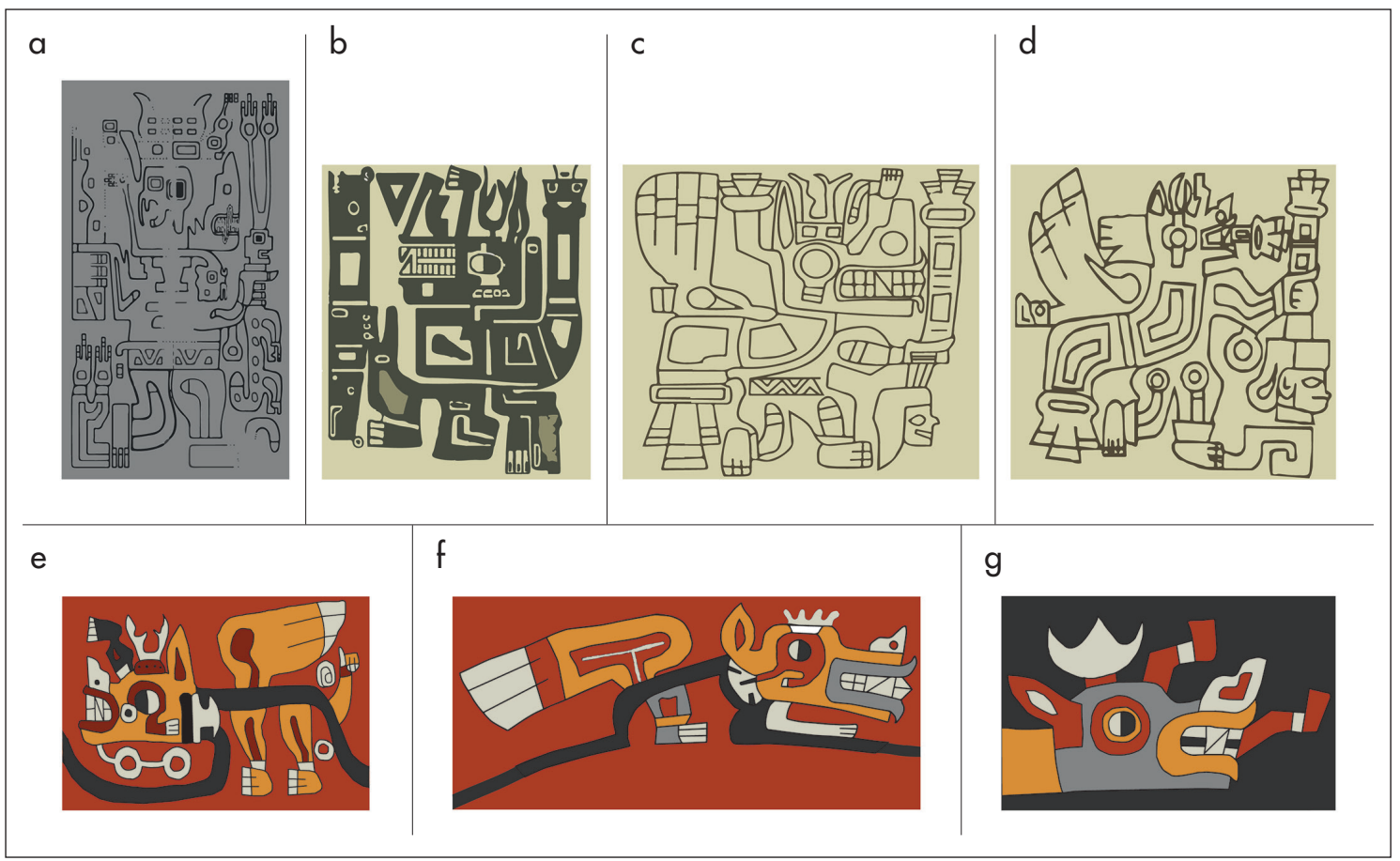

Figura 3. Ejemplos del tema del venado devorador: a) textil de Azapa (sobre la base de Conklin 1983); b) tubo de hueso de San Pedro de Atacama; c, d) tubos de hueso grabados (sobre la base de Trigo \& Hidalgo 2018); e) jarra de Kherikala (sobre la base de Trigo \& Hidalgo 2018); f) keru de Tiwanaku (sobre la base de Posnansky 1957); g) vaso de Pariti. Figure 3. Examples of the devouring deer motif: a) textile from Azapa (based on Conklin 1983); b) tube of bone from San Pedro de Atacama; $c$, d) engraved tubes of bone (based on Trigo \& Hidalgo 2018); e) Kherikala jar (based on Trigo \& Hidalgo 2018), f) keru from Tiwanaku (based on Posnansky 1957); g) Pariti vessel.

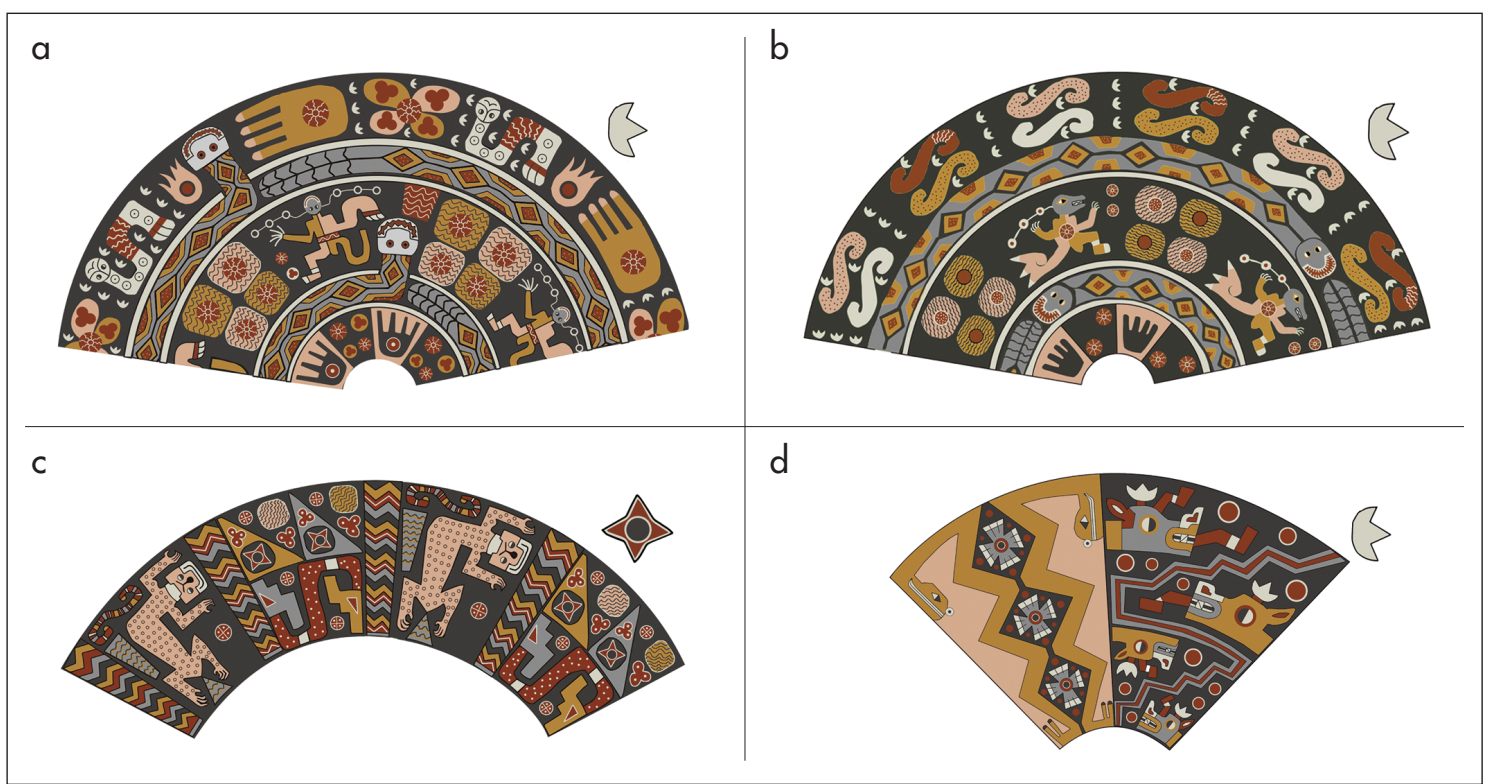

Figura 4. Aparición de motivos relacionados con la iconografía del venado en cerámica de Pariti: a) astas en chiallador PRT00215; b) astas en challador PRT00217; c) círculo negro con puntas en chiallador PRT00241; d) astas en vaso PRT00219. Figure 4. Occurrence of motifs related to deer iconography in Pariti pottery: $\boldsymbol{a}$ ) antlers in challador PRT00215; $\boldsymbol{b}$ ) antlers in challador PRT00217; $\boldsymbol{c}$ ) black circle with spikes in challador PRT00241; d) antlers in vessel PRT00219. 


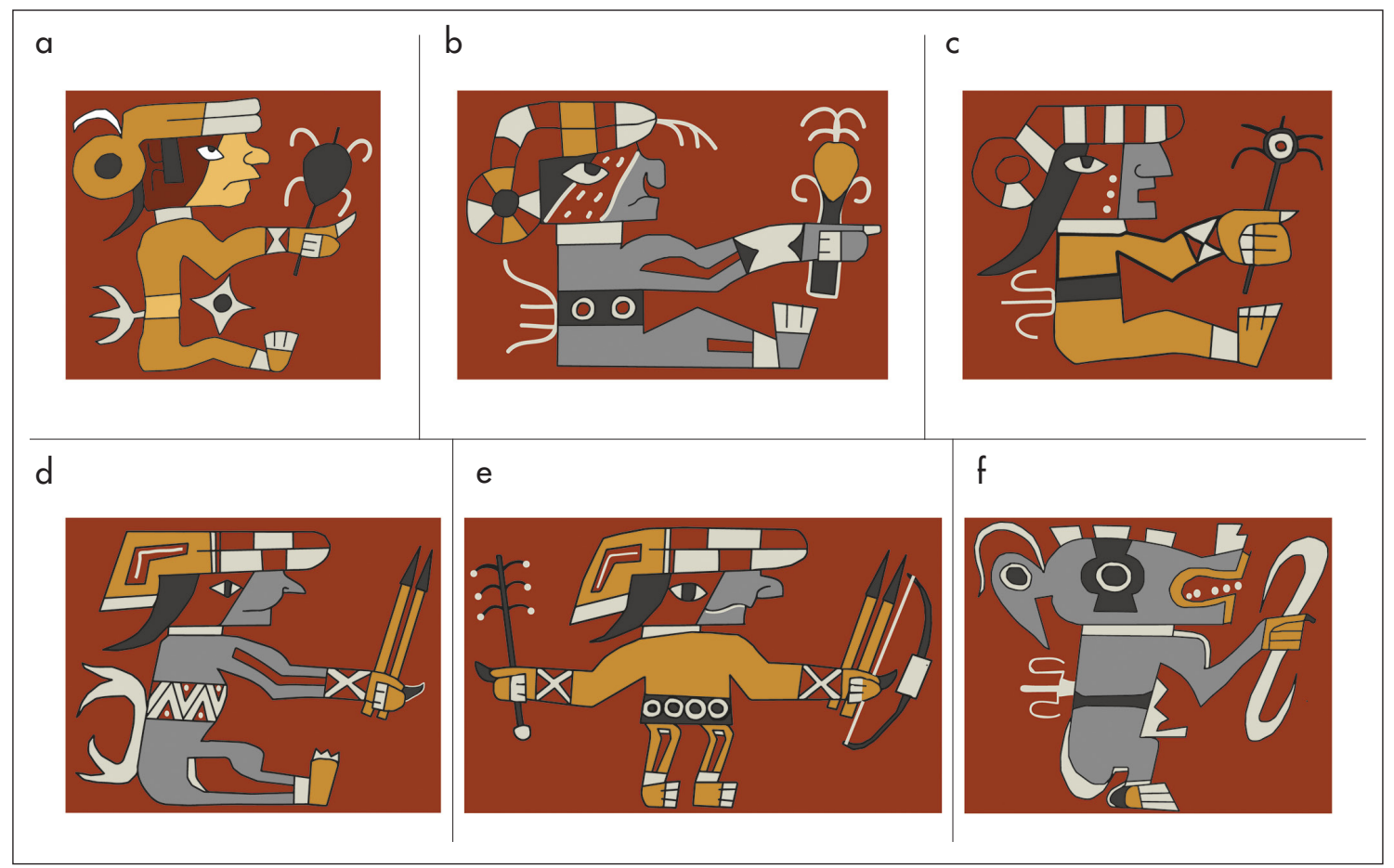

Figura 5. Ejemplos de tema del humano sedente en relación con astas de venado: a, b, c, d, e) keru de Tiwanaku (sobre la base de Posnansky 1957); f) keru de Cochabamba (sobre la base de Goldstein \& Rivera 2004). Figure 5. Examples of the seated human motif in relation to deer antlers: $\boldsymbol{a}, \boldsymbol{b}, \boldsymbol{c}, \boldsymbol{d}, \boldsymbol{e}$ ) Tiwanaku keru (based on Posnansky 1957); f) Cochabamba keru (based on Goldstein \& Rivera 2004).

pero se encuentran en un keru de Tiwanaku (Posnansky 1957: plancha XXII), asociados a un tema también poco frecuente: el humano sedente -de color naranja, con rostro pintado, ojo ovoidal con pupila redonda, cabellera larga $y$ un tocado multicolor- que sostiene en una mano un objeto ovoide negro. El asta de venado se presenta en la espalda del personaje, como si estuviese amarrada a la faja (fig. 5a). Dibujos lineares en blanco, parecidos a astas de venado tripartitas o cuadripartitas, se encuentran en la misma posición en todas las imágenes del humano sedente, en tres kerus similares (Posnansky 1957: planchas xx, XXII, XXIII). En dos casos los personajes, de color naranja o gris, sostienen en la mano el objeto redondo $\mathrm{u}$ ovoide (fig. $5 \mathrm{~b}$ y c), en tanto el tercero carga un par de flechas y alterna con una figura humana erguida, que porta también un arco (fig. $5 \mathrm{~d}$ y e).

Para completar esta secuencia, tenemos un keru rojo de Cochabamba, actualmente en el Cleveland Museum of Art, Estados Unidos (Goldstein \& Rivera 2004: 169). En él se presentan repeticiones grises y naranjas de un cérvido en posición sedente (fig. 5f). Aunque estilizados, se observan los labios en gancho, los colmillos y las astas, cortadas o brotando. En la espalda se observa un dibujo lineal tripartito en blanco, y el personaje sostiene, en vez del objeto ovoide o las flechas, una doble curva blanca de difícil interpretación.

\section{DISCUSIÓN E INTERPRETACIONES}

$\mathrm{Al}$ examinar las imágenes del venado tiwanakota, algunos aspectos hacen eco con las poéticas andinas y amazónicas que revisamos en la primera sección. El venado es parte de un dominio iconográfico poblado por serpientes, felinos y aves rapaces, seres sallqa en algunas taxonomías andinas. Tanto en imágenes tridimensionales como bidimensionales, este dominio privilegia la metamorfosis, el consumo y la fluidez entre especies. El venado se halla ausente del mundo de imágenes anatómicamente exactas, dedicado preponderantemente a llamas y patos, animales de crianza humana o uywa.

Las imágenes de venado reúnen en sus cabezas componentes de humano, felino y ave, pero nunca incorporan componentes de camélido ni ofidio. Camélido 
y cérvido son mutuamente excluyentes: no hay pieza tiwanakota que incluya ambos animales. Por ejemplo, los camélidos son los mayores protagonistas del mundo de las láminas trabajadas de oro y plata, del que los venados están completamente ausentes. Camélidos y cérvidos podrían ser equivalentes: ambos son ganado, pero son metonimias de ámbitos opuestos, como la crianza humana y la crianza no humana, ocasionando esta separación radical. En cuanto a la dicotomía cérvido y serpiente, ambos seres son capaces de presentarse en la misma pieza, como en el vaso PRT00219 de Pariti, aunque en paneles separados y jamás fusionados. Sin embargo, el venado devorador puede poseer un cuerpo de voluta que recuerda algunas imágenes ofídicas tiwanakotas (Villanueva 2015), y ambos comparten los colmillos felínicos como un rasgo esencial. En cierto sentido, la relación del cérvido y el ofidio con el felino es equivalente y opuesta: la serpiente incorpora frecuentemente cabeza felínica, y el venado incorpora cuerpo y patas felínicas. Esta complementariedad recuerda la oposición amazónica entre veneno y bezoar, o entre vida eterna y vejez prematura, que opone a ambos animales.

Ingresando a la imagen del cérvido, su amplia nariz escalonada, de ollares frontales, es un guiño sugerente a la poética andina del venado como metáfora del glaciar. Su potente soplo, causante de avalanchas y waykus, lo ubica como la imagen tiwanakota más vinculada a la montaña nevada; las astas blancas como invocación de la nieve podrían reforzar este vínculo desde una poética atmosférica basada en el color. Previamente hemos planteado que, en la iconografía tiwanakota, el felino gris concedería atmósferas acuáticas y lluviosas, y el ave amarilla convoca atmósferas cálidas y brillantes (Villanueva 2016). Siguiendo este razonamiento, como hipótesis, el venado de astas blancas permitiría a los humanos dialogar y aplacar las atmósferas heladas e impredecibles del glaciar.

La peligrosidad del venado, en su soplo y sus pronunciados colmillos, enfatiza su relación andina y amazónica con la muerte. A diferencia de otros animales, no existen imágenes de cérvido en Tiwanaku que no estén asociadas a la toma o el consumo de partes anatómicas humanas: la cabeza en el caso del decapitador, y las piernas o brazos en el venado devorador. La relación de alguna imagen de venado con cráneos humanos refuerza este vínculo. Así, en sus dos versiones plantea ecos de los mitos andinos y amazónicos sobre el venado "comedor de hombres", y su paso de una humanidad predadora a una animalidad de peligrosidad latente. Como en el Manuscrito de Huarochirí o en el mito tikuna del dios Dyai, el venado tiwanakota cambia los atributos humanos de un decapitador bípedo, sin astas, a veces sin colmillos, pero armado de un hacha, por los atributos más bestiales de un ser cuadrúpedo, astado y que devora extremidades humanas. Las imágenes intermedias, con atributos de ambas versiones, evocan precisamente la poética de un proceso, de una metamorfosis entre dos estados del venado. El venado devorador, con los labios ganchudos y grandes colmillos, las patas de felino y las alas de ave, sugiere un vínculo notable con las nociones amazónicas del jaguar-venado, un ser peligroso asociado con los dueños de los animales y la ética de la cacería. El color ambiguo, a veces gris, a veces naranja, del venado tiwanakota enfatiza ese carácter ambiguo de "cambiapieles", de cérvido y felino, de predador disfrazado de presa.

Y, finalmente, las ideas amazónicas y andinas que ubican a los dueños de los animales en la bóveda nocturna se perciben en el asta de venado sobre fondo negro, entre las constelaciones. El asta es una estrella observada por los cazadores, y se convierte en una metonimia del venado apropiado por el humano sedente. En esta imagen, una de las pocas que remiten a la cacería en la iconografía tiwanakota, encontramos la poética de la presa, del venado muerto y su relación con arcos, flechas y la observación del cielo nocturno. Encontrar excepcionalmente cérvidos sin astas imitando la posición del cazador, sugiere un movimiento de retorno, quizá una mirada desde una perspectiva no humana: el cazador convertido en presa o el venado como el animal más humano.

\section{CONCLUSIONES}

El venado tiwanakota expresa la transición de un cazador humano-cérvido, a un venado felínico devorador de humanos, a una presa cazada por humanos, $y$ al cazador humano convertido en presa. Retomando nuestra introducción, esta imaginería del venado dista mucho de ser la representación o imagen "naturalista" de un animal, o de una serie de actividades económicas o rituales. No resulta de una observación superficial, sino de un involucramiento profundo con el entorno mediante una poética de la cacería, en relación con la muerte y el consumo, con la montaña glaciar y sus 
accidentes, con el cielo nocturno, con los dueños de los animales, los predadores y las presas, su inestabilidad, procesos y transformaciones.

A la vez, es fundamental no pensar estas imágenes como reflejos pasivos de ideas. Así como emergieron de la poética de la caza, las imágenes del venado permitieron a las comunidades humanas relacionarse con el mundo mediante la manipulación de esculturas y vasos para brindar y challar, tejidos, tubos y tabletas de uso psicotrópico. Nuestra hipótesis es que los humanos tiwanakotas pudieron dialogar con los dueños de los animales, con los glaciares nevados y con el cielo estrellado, por medio de estas imágenes -junto con otras herramientas materiales-, procurando jornadas de cacería exitosas y respetuosas, libres de castigo y de muerte, de encuentros indeseados con el temido devorador de hombres, y de desastres provocados por el soplo destructor de los glaciares.

Esta forma de cocrear el mundo para la cacería, permite un ingreso inusual a la sociedad tiwanakota, tradicionalmente considerada agropastoril y urbana. Las imágenes de caza en Tiwanaku han sido descuidadas a pesar de las evidencias iconográficas y materiales de consumo y uso de animales de caza. Probablemente este fenómeno se deba a la herencia nacionalista aún patente sobre la arqueología de Tiwanaku: el "Estado andino" y la consideración de la cacería como un signo de estadios menores de desarrollo, o de un carácter esencialmente amazónico o "silvícola", sesgan nuestras narrativas sobre el pasado prehispánico. Hemos intentado un antídoto a esos sesgos, al examinar las poéticas de la cacería andina y amazónica, para sugerir que la iconografía tiwanakota incorpora elementos de ambos sustratos. Tal vez podemos repensar los Andes y la Amazonía prehispánicos como puntos de una línea, con múltiples confluencias e interacciones. Y quizá ese pasado, en el contexto político presente, nos permita construir un futuro con menos polarización y exclusiones.

Agradecimientos Debo agradecer a los directores del Proyecto Arqueológico Chachapuma, Antti Korpisaari y Jédu Sagárnaga, por su apertura, que me facilitó el acceso al rico universo iconográfico de la isla Pariti. Asimismo, al Museo Nacional de Etnografía y Folklore por permitirme desarrollar este texto en el marco de un año dedicado a los lenguajes y poéticas. Finalmente, a los editores del Boletín del Museo Chileno de Arte Precolombino y a los revisores anónimos cuyos comentarios aportaron de modo importante al texto final.

\section{NOTAS}

${ }^{1}$ En la actual Bolivia existen siete especies de cérvidos. En las tierras altas, la taruka o venado andino (Hippocamelus antisensis) y el venado de cola blanca (Odocoileus virginianus). En las tierras bajas, el venado de las pampas (Ozotoceros bezoarticus), el ciervo de los pantanos (Blastocerus dichotomus) y tres especies de corzuela (género Mazama) (Ríos \& Aliaga 2013).

${ }^{2}$ Cría de vicuña / cría de venado / siempre he sido / la cría de mi amado.

${ }^{3}$ Venado de los cerros / mi padre, errante, llorará por mí / Vicuña de los cerros / mi madre, errante, sufrirá por mí.

${ }^{4}$ Chullpa es un término aymara que hace referencia tanto a las torres funerarias construidas en el Intermedio Tardío, como a los cuerpos humanos contenidos en las mismas. Sin embargo, designa también todo lo antiguo, usualmente lo prehispánico. Esta idea proviene del concepto de los chullpas, miembros de una sociedad prehumana y frecuentemente presolar: el mito suele contar que los chullpas vivían en las torres funerarias y fueron sorprendidos dentro de ellas por el Sol, que al salir los mató. Para muchas comunidades andinas son los autores y los guardianes de los lugares y cosas antiguas, y es peligroso entrar en contacto con ellos.

${ }^{5}$ El soplo es también el sonido onomatopéyico phusa, phusa, atribuido al venado en los wayñus de Qaqachaka (Arnold \& Yapita 1992: 59).

${ }^{6}$ También se han detectado astas de venado en contextos de excavación de la isla Pariti (Trigo \& Hidalgo 2018).

${ }^{7}$ En el caso de la ofrenda de Pariti, aparecen excepcionalmente ceramios modelados en forma de águilas, lagartijas, insectos e hipocampos, y aplicaciones plásticas de murciélagos, osos y simios (Korpisaari et al. 2009; Korpisaari \& Pärssinen 2011; Sagárnaga 2014). Existe también una pequeña efigie metálica de zorro documentada en la pirámide de Akapana (Manzanilla et al. 1990).

${ }^{8}$ En su estudio sobre iconografía de las túnicas wari, Bergh (2009) propone que determinadas imágenes serían de cérvidos o camélidos debido a que sostienen un báculo con una mano de tres dedos. Dado que estas imágenes no poseen la nariz escalonada, astas ni labios en gancho, no las consideramos como imágenes de cérvidos en este texto.

\section{REFERENCIAS}

Albarracín-Jordán, J. 1996. Tiwanaku: Arqueología regional $y$ dinámica segmentaria. La Paz: Plural.

Angelo, D. 2005. La Arqueología en Bolivia. Reflexiones sobre la disciplina a inicios del siglo xxi. Arqueología Suramericana 1 (2): 185-211.

Angelo, D. 2006. Líneas de tiempo y círculos de consumo: acerca de las relaciones de interacción en el altiplano sur 
andino. En Esferas de interacción prehistóricas y fronteras nacionales modernas: los Andes sur centrales, H. Lechtman, ed., pp. 127-158. Lima: IEP/IAR.

Angelo, D. \& J. CAPRILes 2000. La importancia de las plantas psicotrópicas para la economía y relaciones de interacción en el Altiplano sur andino. Complutum 11: 275-284.

Arnold, D. 2016. Más allá de "lo andino": repensando Tiwanaku desde las tierras bajas. Textos Antropológicos 17 (1): 111-134.

Arnold, D. \& E. Espejo 2013. Lazos forestales: técnicas y diseños de los tirantes de bolsas personales de Mojocoya, como expresiones del alcance de los intercambios regionales en los Andes Sur Centrales durante el Horizonte Medio. Arqueoantropológicas 3 (3): 59-92.

Arnold, D. \& J. Yapita 1992. Sallqa: dirigirse a las bestias silvestres en los Andes Meridionales. En Hacia un orden andino de las cosas, D. Arnold, D. Jiménez \& J. Yapita, eds., pp. 175-212. La Paz: HisBol.

Arnold, D. \& J. YAPITA 1998. Río de vellón, río de canto. La Paz: ILCA.

Baitzel, S. \& D. Trigo 2019. The Tiwanaku camelid sacrificer: origins and transformations of animal iconography in the Middle Horizon (AD 400-1100) state expansion. Ñawpa Pacha 39 (1): 31-56.

Bendezú, E. 2003. Literatura quechua. Lima: Universidad Ricardo Palma, Editorial Universitaria.

Bennett, W. 1934. Excavations at Tiahuanaco. Anthropological Papers of the American Museum of Natural History, vol. 34. Nueva York: American Museum of Natural History. <http://hdl.handle.net/2246/79> [consultado: 24-08-2021].

Bergh, S. 2009. The bird and the camelid (or deer): a ranked pair of Wari tapestry tunics? En Tiwanaku. Papers from the 2005 Mayer Center Symposium at the Denver Art Museum, M. Young-Sánchez, ed., pp. 225-245. Denver: Denver Art Museum.

CAPriles, J. 2002. Intercambio y uso ritual de fauna por Tiwanaku: análisis de pelos y fibras de los conjuntos arqueológicos de Amaguaya, Bolivia. Estudios Atacameños 23: 33-52.

Conklin, W. 1983. Pucara and Tiahuanaco tapestry: time and style in a Sierra weaving tradition. Nawpa Pacha 21 (1): 1-44.

Couture, N. \& K. SAmpeck 2003. Putuni: a history of palace architecture in Tiwanaku. En Tiwanaku and its Hinterland 2, A. Kolata, ed., pp. 226-263. Washington DC: Smithsonian Institution Press.

EscobAR, A. 2013. En el trasfondo de nuestra cultura: la tradición racionalista y el problema del dualismo ontológico. Tabula Rasa 18: 15-42.

Espejo, E. 2006. Phaqar kirki T'ikha Takiy. Canto a las flores. La Paz: Editorial Pirotecnia.

Garcilaso de La Vega, I. 1968 [1609]. Comentarios reales: el origen de los Incas. Barcelona: Editorial Bruguera.

Goldstein, P. \& M. Rivera 2004. Arts of greater Tiwanaku: an expansive culture in historical context. En Tiwanaku.
Ancestors of the Inca, M. Young-Sánchez, ed., pp. 150-185. Denver: Denver Art Museum.

Guamán Poma de Ayala, F. 1993 [1615]. El Primer Nueva Coronica y Buen Gobierno, F. Pease G.Y., ed. Lima: Fondo de Cultura Económica.

Hernández, A. (Ed.) 1983. Poesía popular andina. Tomo 2. Quito: Ediciones Instituto Andino de Artes Populares, Convenio "Andrés Bello".

Horta, H. 2016. The chin adornment of the highlands lords as a symbol of historical continuity and ethnic emblem in the Southern Andes (500-1600 AD). Chungara 48 (3): 365-382.

Horta, H., M. Paulinyi, B. Santander \& J. Echeverría 2020. Una nueva faceta para "El Sacrificador". Iconografía Tiawanaku en tubos de hueso de San Pedro de Atacama, Chile (400-1000 DC). Boletín del Museo Chileno de Arte Precolombino 25 (2): 97-126.

Huxley, F. 1960. Aimables sauvages. París: Plon.

IbARra Grasso, D. 1982. Ciencia astronómica y sociología incaica. La Paz y Cochabamba: Los Amigos del Libro.

IngOLD, T. 2000. The perception of the environment. Londres y Nueva York: Routledge.

JAnusek, J. 2008. Ancient Tiwanaku. Cambridge: Cambridge University Press.

KARADimAS, D. 2014. Las alas del tigre: acercamiento iconográfico a una mitología común entre los Andes prehispánicos y la Amazonía contemporánea. En Amazonía. Memorias de las Conferencias Magistrales del 3er Encuentro Internacional de Arqueología Amazónica, S. Rostain, ed., pp. 203-223. Quito: Ekseption Publicidad.

Kolata, A. 1986. The agricultural foundations of the Tiwanaku State: a view from the heartland. American Antiquity 51 (4): 748-762.

Korpisaari, A. \& M. PÄrssinen 2011. Pariti. The ceremonial tiwanaku pottery of an island in Lake Titicaca. Helsinki: Finnish Academy of Science and Letters.

KorpisAari, A., I. SÄÄKSJÄrvi \& M. SAlo 2007 Ms. Evidencias de contactos entre la sierra, la ceja de selva y la selva baja en el arte de la cultura Tiwanaku.

Lienhard, M. 2005. La cosmología poética en los huaynos quechuas tradicionales. Acta Poética 26 (1-2): 485-513.

Llagostera, A. 2006. Contextualización e iconografía de las tabletas psicotrópicas Tiwanaku de San Pedro de Atacama. Chungara 38 (1): 83-111.

LozA, C. B. 2007. El atado de remedios de un religioso/médico del período Tiwanaku: miradas cruzadas y conexiones actuales. Bulletin de l'Institut Français d'Études Andines 36 (3): 317-342.

Manzanilla, L., L. Barba \& M. R. Baudoin 1990. Investigaciones en la pirámide de Akapana, Tiwanaku, Bolivia. Gaceta Arqueológica Andina v (20): 81-107.

Michel, M. 2009 Ms. Retrospectiva de la arqueología en Bolivia. Ponencia inédita presentada en el panel "La Bolivia del siglo xxi y los desafíos de las ciencias sociales”, Plan Estratégico e Institucional de la Facultad de Ciencias 
Sociales de la UMSA, 2010-2015, realizado entre el 1 el 4 de septiembre de 2009 en La Paz, Bolivia.

Millones, L. \& R. Mayer 2012. La fauna sagrada de Huarochirí. Lima: IEP-IFEA.

Molinié-Fioravanti, A. 1985. Tiempo del espacio y espacio del tiempo en los Andes. Journal de la Société des Américanistes 71: 97-144.

Paredes, R. 1963. Mitos, supersticiones y supervivencias populares de Bolivia. La Paz: Ediciones "Isla".

Polo De Ondegardo, J. 1916 [1571]. Informaciones acerca de la religión y gobierno de los Incas. Lima: Imprenta y Librería San Martín y Cía.

Ponce SANGINés, C. 1972. Tiwanaku: espacio, tiempo y cultura. Ensayo de síntesis arqueológica. La Paz: Academia Nacional de Ciencias de Bolivia.

Posnansky, A. 1957. Tihuanacu, la cuna del hombre americano, tomo III. La Paz: Ministerio de Educación.

Pucher De Kroll, L. 1950. El auquénido y la cosmogonía amerasiana. Potosí: Universidad Tomás Frías.

Renard-Casevitz, F. M. 1979. Su-açu: essai sur les cervidés de l'Amazonie et sur leur signification dans les cultures indiennes actuelles. París-Lima: Institut Français d’Études Andines.

Ríos, B. \& E. Aliaga 2013. Los ciervos de Bolivia. Bolivia Ecológica 63: 1-34.

Rivera, C. 2012. Tecnología textil durante el período Formativo en los valles Central y Alto de Cochabamba. Arqueoantropológicas 2: 143-162.

SAgÁRnAgA, J. 2014. Monos y exotismo en Tiwanaku: una perspectiva desde Pariti. Chachapuma 7: 44-51.

Sagárnaga, J. \& A. Korpisaari 2007. Hallazgos en la isla de Pariti echan nuevas luces sobre los "chachapumas" tiwanakotas. Chachapuma 2: 6-28.

Sánchez, W., M. Bustamante \& J. Villanueva 2016. La Chuwa del cielo. Los animales celestiales y el ciclo anual altiplánico desde la biografía social de un objeto. La Paz: MUSEF.

Torres, C. 1987. The Iconography of the Prehispanic Snuff Trays from San Pedro de Atacama, Northern Chile. Andean Past 1: 191-245.

Trigo, D. \& R. Hidalgo 2012. Tiwanaku Huari. Los miembros inferiores y sus representaciones en las ofrendas del Horizonte Medio (el simbolismo del rito de corte de piernas en la iconografía de los Andes). La Paz: Producciones cima.

Trigo, D. \& R. Hidalgo 2018. El decapitador venado en la iconografía Tiwanaku: orígenes, desarrollo y significados. Arqueología Boliviana 4: 131-161.

Urton, G. 1981. Animals and astronomy in the quechua universe. Proceedings of the American Philosophical Society 125 (2): 110-127.

Villanueva, J. 2007. Las escudillas del rasgo 1 en la isla de Pariti: interpretación y consideraciones desde un enfoque iconográfico. Chachapuma 1: 53-63.

Villanueva, J. 2015. En torno a concepciones del tiempo en Tiwanaku. Consideraciones en base a la iconografía de los chialladores de Pariti. Cuaderno de Campo 6: 1-19. Villanueva, J. 2016. Aves doradas, plantas plumarias y ojos alados. Vías para interpretar la iconografía aviaria en Tiwanaku. Anales de la Reunión Anual de Etnología 29: 233-249.

VillanueVA, J. 2018. Las calabazas cerámicas. Imitación de materiales vegetales y culto al agua en la cerámica Tiwanaku de la isla Pariti. Anales de la Reunión Anual de Etnología 31: 97-118.

WAlter, D. 2017. El Tarugo (Hippocamelus antisensis, Cervidae): mitos, creencias y prácticas en la Cordillera Blanca del Perú. Revista de Glaciares y Ecosistemas de Montaña 2: $103-114$.

Webster, A. \& J. Janusek 2003. Tiwanaku camelids. Subsistence, sacrifice, and social reproduction. En Tiwanaku and its Hinterland 2, A. Kolata, ed., pp. 343-362. Washington DC: Smithsonian Institution Press.

Zerries, O. 1959. Las constelaciones como expresión de la mentalidad cazadora en Sudamérica. Estudios Americanos 88-89: 1-18. 